\title{
Results of Salmonella Typhi Culture in Patients with Suspected Typhoid Fever, Treated in the Department of Child Health Medical School, Padjadjaran University, Hasan Sadikin General Hospital Bandung
}

\author{
by \\ NANAN SEKARWANA, HERRY GARNA and AZHALI M.S.
}

(From the Department of Child Health, Medical School, Padjadjaran University/ Hasan Sadikin General Hospital, Bandung)

\begin{abstract}
From October to December 1984, examination has been carried out on Salmonellatyphi cultures from blood, bone marrow, faeces and urine of 43 patients suffering from suspected typhoid fever treated in the Department of Child Health, Medical School/ Hasan Sadikin General Hospital, Bandung.

It was apparent that among these 43 patients, $51,2 \%$ were males and $48,8 \%$ females. The greater number of them were more than 5 years old $(64,4 \%)$.

The results of Salmonella-typhi cultures were obtained |from $65 \%$ of the patients, consisting of $65 \%$ positive cultures from bone-marrow and $40 \%$ positive cultures from blood that showed a statistically significant difference $(p<0.05)$.

Likewise, the time for matter-sampling for the examinations was based on the culture results, both on blood-culture and that of bone-marrow, statistically a significant was found $(p<0,05)$, whereas the results of cultures based on previous vaccination history and the administration of chloramphenicol prior to treatment did not differ significantly.

It was obviously clear that the results of bone-marrow culture were more successful compared to those from blood culture, so that it should necessarily be emphasized, as to these examinations on culture from each patient with suspected typhoid fever, especially those patients hospitalized during the third week of their illness.
\end{abstract}




\section{Introduction}

Typhoid fever in developing countries still constitutes a health problem (Abt and Abt, 1969). The diagnosis of this illness is established based on clinical pictures and laboratory examinations (Krugman and Ward, 1974). Classic clinical pictures, since the detection of chloramphenicol became rarely encountered so that frequently difficulties were raised in establishing diagnosis.

An exact diagnosis of typhoid fever was determined when Salmonella typhi could be isolated from examination-matter (Krugman and Ward, 1974). From several examination, these laboratory results did not show any satisfactory pictures yet to make a diagnosis, since a positive result was less than that from working diagnosis made (Sumarmo et al., 1980).

Alisjahbana et al. (1970), Gilman et al. (1975), Seshadri et al. (1977) and Bachtin et al. (1978) found out that the results of examinations on Salmonella-typhi culture from bone-marrow yielded more positive results in comparison with the examinations on culture from blood, faeces and urine.

The purpose of this study is to have a view of the Salmonella-typhi cultures on patients suffering from suspected typhoid fever.

\section{Materials and methods}

This study was performed prospectively on all patients with suspected typhoid fever treated in the Department of Child Health, Medical School of Padjadjaran University/ Hasan Sadikin General Hospital, Bandung, since October up to December 1984. Records were made on these patients with respect to their age,sex, history of chloramphenicol administration prior to treatment, history of vaccination as well as clinical symptoms (fever more than 7 days, headache, delirium, obstipation or diarrhea, dry chopped lips, a furred tongue with hyperemic rims, hepatomegaly/hepatosplenomegaly).

Prior to treatment, blood sample $(5 \mathrm{ml})$ from v.cubiti and bone-marrow tissue $(0.5-1 \mathrm{ml})$ for culture examination were performed. Bone marrow tissue in children older than 2 years was taken from the coxa bone and the tibia bone in those less than 2 years old.

Both matters for examination were incubated in a medium of the bile. At the same time, $3 \mathrm{ml}$ urine and faeces were taken. The faeces was then put into a preserving fluid; urine was centrifuged in order to take its sediment (precipitate).

These four examination-matters were then implanted into Salmonella-Shigella gelatine. The presence of Salmonella typhi was determined by biochemical reactions and confirmed by means of the agglutination-test with a specific antigen.

The examination was considered negative, when after implanting 7 times subsequently, not any suspected colony at all was found. All these examination were carried out at Bio Farma Bandung.

The subjects were grouped based on the results of cultures on Salmonella typhi; those with positive cultures (of blood and bone-marrow) were grouped based on history of vaccination performed as well as the administration of chloramphenicol prior to treatment, and at the time of sampling on the examination-matter. Statistical differences were evaluated by means of the Chi-square test. 


\section{Results}

During three months period, 43 patients Salmonella-typhi cultures were obtained (22 males and 21 fernales) with suspected ty- from 28 patients $(65 \%)$ (Table 1). phoid fever were examined. The positive

Table 1 : Results of Salmonella-typhi culture from blood, bone-marrow, faeces and urine in 28 patients based on age, sex, history of vaccination and chloramphenicol administration prior to treatments

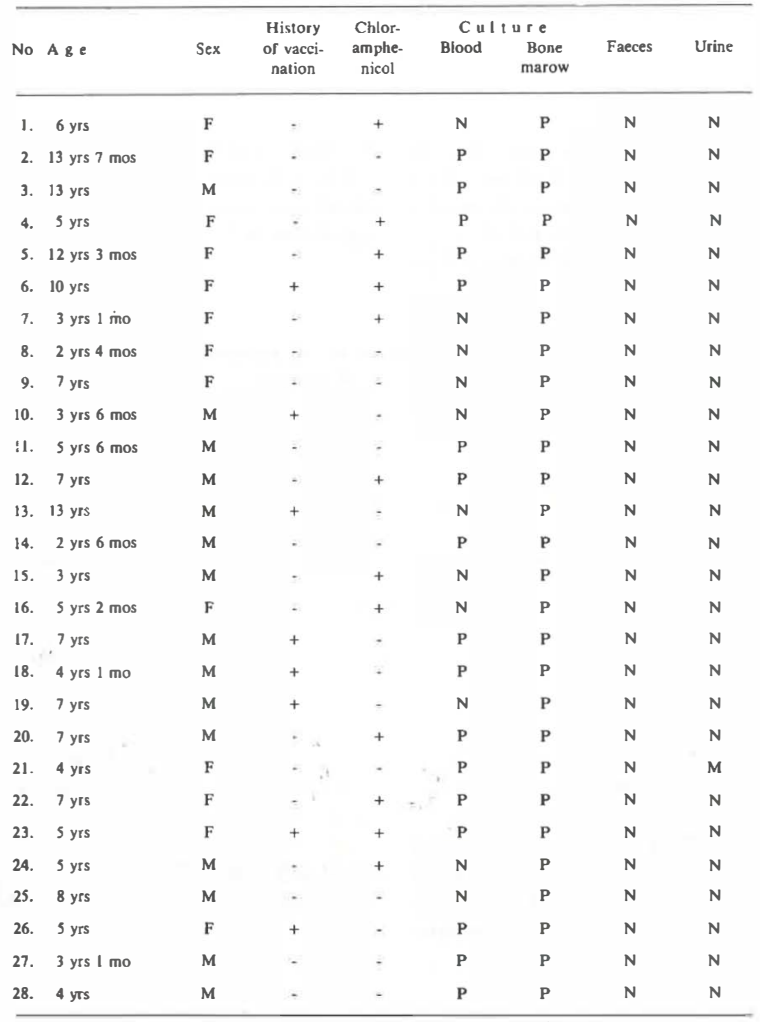


Table 2 : Results of Salmonella-typhi culture in 43 patients with suspected typhoid fever based on the matter of examination

\begin{tabular}{lcc}
\hline Culture of & Number of patients & Positive \\
\hline Blood & 43 & $17(40.0 \%)$ \\
Bone-marrow & 43 & $28(65.0 \%)$ \\
Faeces & 43 & 0 \\
Urine & 43 & 0 \\
\hline
\end{tabular}

From table 2 it is apparent that the positive results of S-typhi cultures from blood and bone marrow were obtained in $17(40.0 \%)$ and 28 patients $(65.0 \%)$, respectively. Whereas S.typhi cultures from the faeces and urine were all negative.

The difference in culture results from blood and bone marrow was statistically significant $\left(\mathrm{x}^{2}=5.2 ; 0.05>\mathrm{p}>0.01\right)$.

Table 3 : Results of Salmonella-typhi culture in 43 patients with suspected typhoid fever based on vaccination prior to treatment

\begin{tabular}{lcccc}
\hline Vaccination & \multicolumn{2}{c}{ Positive } & \multicolumn{2}{c}{ Negative culture } \\
\cline { 2 - 4 } & $\mathrm{N}$ & $\%$ & $\mathrm{~N}$ & $\%$ \\
\hline Positive & 9 & 32.0 & 9 & 60.0 \\
Negative & 19 & 68.0 & 6 & 40.0 \\
\hline Tot a I & 28 & 100.0 & 15 & 100.0 \\
\hline
\end{tabular}

Table 3 shows that $9(32.0 \%)$ of 28 patients with positive Salmonella-typhi culture had received a complete basic vaccinations and had also been revaccinated, whereas 19 patients $(68.0 \%)$ had never received vaccination. Among the 15 patients with negative culture, 9 patients
$(60.0 \%)$ had received a complete basic vaccinations, while 6 patients $(40.0 \%)$ had never been vaccinated.

The difference of culture results from blood and bone marrow were not statistically significant $\left(x^{2}=2.4 ; \mathrm{p}>0.05\right)$. 
Table $4:$ The results of Salmonella typhi culture from blood and bone-marrow in 28 patients with typhoid fever based on the administration of chloramphenicol prior to treatment

Positive culture

Chloramphenicol administration

Yes No

Blood

$7(36.8 \%)$

$10(38.5 \%)$

Bone-marrow

$12(63.2 \%)$

$16(61.5 \%)$

To t a l

$19(100 \%)$

$26(100 \%)$

From table 4 it is apparent that among the 17 patients with positive Salmonella typhi cultures of the blood, 7 patients $(36.8 \%)$ had received chloramphenicol and the other 10 patients $(38.5 \%)$ had not received chloramphenicol prior to treatment. Whereas among the 28 patients with positive Salmonella typhi cultures of the bone marrow, 12 patients $(63.2 \%)$ had received chloramphenicol prior to treatment. The difference in culture results based on the administration of chloramphenicol prior to treatment did not appear to be statistically significant $\left(x^{2}=0.5175\right.$; $p>0.05$ ).

Table 5 : Results of Salmonella-typhi culture. tients with typhoid fever based on the time of sampling matter

\begin{tabular}{|c|c|c|c|c|}
\hline $\begin{array}{l}\text { The time of blood/bone- } \\
\text { marrow sampling }\end{array}$ & Blood & Positive Culture & Bone-marrow & \\
\hline Second week & $15(88.2 \%)$ & 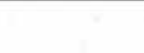 & $16(57.1 \%)$ & 1 \\
\hline Third week & $2(11.8 \%)$ & & $12(42.9 \ddot{9} \%)$ & $\cdots$ \\
\hline Total & $17(100 \%)$ & & $28(100 \%)$ & \\
\hline
\end{tabular}

Table 5 .shows that during the second week, there were more positive results of S.typhi in blood culture (88.2\%) compared with in the thirdweek $(11.8 \%)$, likewise was the results in bone-marrow culture (second week $57.1 \%$, third week $42.9 \%$ ).

The difference of positive reşults in S.typhi culture from blood and bonemarrow ed on the time of sampling was statistically significant $\left(x^{2}=3.9597 ; 0.05 \gg p>0.01\right)$. 


\section{Discussion}

In establishing the diagnosis of tyhoid fever, the S.typhi culture from the blood is frequently performed, but this examination is influenced by several factors such as the time of blood sampling, the proceeding therapy performed and the amount of blood taken (Seshadri et al., 1977).

Salmonella typhi could be isolated from the patient's blood in an acute phase, that is from the seventh to the tenth day of illness and at the time of relapse. During the first week positive results can be achieved to the amount of $80-90 \%$ and when tapped during the subsequent weeks, the percentage of the positive results decreases (Wilcock and Manson-Bahr, 1975; Gilman et al., 1975). However the culture of bone-marrow aspirate may yield positive results even when blood culture is negative (Gilman et al., 1975; Seshadri et al., 1977). This may be explained as follows: despite a phagocytosis process of Salmonella typhi by the reticulo-endothelial system occurs, some of the bacteria may survive in the reticuloendothelial system of bone-marrow, although the blood is already sterile. This causes a positive result on tissue culture of the bonemarrow (Seshadri et al., 1977).

Alisjahbana et al., (1970) from their study in Bandung found that $83 \%$ of 63 children with suspected typhoid fever showed positive Salmonella typhi culture of the bonemarrow and $50.9 \%$ of the blood. Bachtin et al. (1978) also found among 63 patients with suspected typhoid fever positive results of Salmonella typhi culture to the amount of $67 \%$ from bone-marrow and $38 \%$ from the blood. In this particular study among the 43 patients with suspected typhoid fever $65 \%$ showed positive S.typhi culture from the bone-marrow and $40 \%$ from the blood, from faeces and urine the results were negative.
The bone-marrow culture showed a greater percentage than that from blood culture, so that if bone-marrow culture had not been performed, as many as 11 children $(25.6 \%)$ would have escaped from the exact diagnosis.

According to Gilman et al. (1975) the smaller numbers of positive result of the S.typhi culture from the blood was supposed to be due to the fact that the patient had received antibiotics prior to performing the blood culture. From this study, however, it was apparent that the administration of chloramphenicol prior to treatment did not influence either on the results of blood culture or the culture of bone-marrow ( $p>0.05$ ): which is similar to the finding of Bachtin et al. (1978) in Yogyakarta.

Azhali and Singadipoera (1978) reported that as many as $53.5 \%$ of the patients with suspected typhoid fever had never received vaccination prior to the onset of the illness. It seemed that immunization could decrease the morbidity of the illness. In this study, among 28 patients with suspected positive S.typhi culture, $68.0 \%$ had never received vaccination before, the other $32.0 \%$ had received a basic vaccination. However, based on statistical calculations, the history of vaccination during infancy did not influence the results of the culture ( $p>0.05$ ). This might be related to statement of Abt and Abt (1969) that vaccination performed against typhoid could protect the infant for three years; should they live in an endemic area, however, the vaccination should be repeated yearly.

Gilman et al. (1975) brought forward that the results of positive S.typhi cultures from the blood and bone-marrow were decreasing with the longer duration of the course of the illness. This fact is in accor- 
dance with this study, where the result of the blood culture during the second week increased to $88.2 \%$ and during the third week it changed into $11.8 \%$; likewise, in the culture on bone-marrow, the results during the second week was $57.1 \%$, while during the third week it decreased to $42.9 \%$ : the result of the culture of the bone-marrow, however, did not show a decrease as rapidly as that of the blood culture $(0.05$ $>\mathrm{p}>0.01$ ).

\section{Conclusion}

This study revealed that the result of the examination on S.typhi culture on bone-marrow was much more than the result of examination on cultures of blood, faeces and urine. The examination on the
S.typhi culture of the bone-marrow should necessarily be emphasized on patients suffering from typhoid fever, especially on those who were admitted during the third week of their illness.

\section{Achnowledgement}

We would like to thank Dr. Stephen Iwan Sumara, Chief of the Department of Bacteriology, Bio Farma Laboratory of
Public Health Bandung, and his staff for their valuable suggestions and assistance in carrying out this study.

\section{REFERENCES}

I. ABT, I.A.; ABT, A.F.: Typhoid fever; in Brennemann's Practice of Pediatrics, pp. 1-30 (Hoeber Medical Division, 1969).

2. ALISJAHBANA, A.; SUMARTINI, T.; WIRADISURIA, S.; SUGIRI: Salmonellosis in infants and children in Bandung. Paediatr. Indones. 10:67-77 (1970).

3. AZHALI, M.S.; SINGADIPOERA, B.: Gambaran klinis dan laboratoris typhus abdominalis di Bagian Ilmu Kesehatan Anak FKUP/RSHS Bandung. Naskah simposium typhus abdominalis. Disampaikan pada Pertemuan/Pekan Ilmiah FKUP/RSHS Bandung, Januari 1978.

4. BACHTIN, M.; SURJANTORO, P.; NELWAN; SOENARTO, J.; ISMANGOEN: Evaluation on typhus abdominalis treated by general practitioner in Yogyakarta. Paediatr. Indones. $18: 185-190$ (1978).

5. GILMAN, R.H.; TERMINEL, M.; LEXINE, M.M.; HERDANEZMEDOZA, P.; HOR-
NICK, R.B.: Relative efficacy of blood, urine, rectal swab, bone-marrow and rose spot cultures for recovery of Salmonella typhi in typhoid fever. Lancet i : 1211 (1975).

6. KRUGMAN, S.; WARD, R.: Infectious diseases of children and adults; 5th ed., pp. 254-263 (Mosby, St. Louis 1974).

7. SESHADRI, V.; NATARAJAN, K.; SUNDARAVELU, T.; JEPEGNANUM, J.; JEVARAY, S.D.; GNANAVEDAN: Efficacy of bone-marrow culture in enteric fever, J. Asso. Phys. Ind., 25 : 561-464 (1977).

8. SUMARMO, MUSLIM A. NATHIN; SOFYAN ISMAEL; TUMBELAKA, W.A.F.J.: Masalah demarn tifoid pada anak. Medika hal. 517-520, Th. 6, Septernber (1980).

9. WILCOCK, C.; MANSON-BAHR, P.E.C.: Typhoid fever; in Manson's tropical diseases; 17th ed., pp. 531-545 (Elbs and Balliiere Tindall, London 1975). 